\title{
Autoantibodies to human tryptophan hydroxylase and aromatic L-amino acid decarboxylase
}

\author{
Chiara Dal Pra ${ }^{1,2}$, Shu Chen ${ }^{1}$, Corrado Betterle ${ }^{3}$, Renato Zanchetta ${ }^{3}$, Vivienne McGrath ${ }^{1}$, Jadwiga Furmaniak ${ }^{1,2}$ \\ and Bernard Rees Smith ${ }^{1,2}$ \\ ${ }^{1}$ FIRS Laboratories, RSR Ltd, Parc Ty Glas, Llanishen, Cardiff CF14 5DU, UK, ${ }^{2}$ Department of Medicine, University of Wales College of Medicine, \\ Heath Park, Cardiff CF14 4XN, UK and ${ }^{3}$ Department of Medical and Surgical Sciences, University of Padua, Via Ospedale, Civile 105, 35128 Padua, \\ Italy \\ (Correspondence should be addressed to J Furmaniak; Email: firs@rsrltd.eclipse.co.uk) \\ (C Dal Pra is now at Department of Medical and Surgical Sciences, University of Padua, Via Ospedale, Civile 105, 35128 Padua, Italy)
}

\begin{abstract}
Objective: To assess the prevalence of autoantibodies (Abs) to tryptophan hydroxylase (TPH) and aromatic L-amino acid decarboxylase (AADC) in patients with different autoimmune diseases and to analyse their respective epitopes.

Design: TPH and AADC Abs were measured in an immunoprecipitation assay using ${ }^{35} \mathrm{~S}$-labelled fulllength and fragments of TPH and AADC.

Methods: Patients with different autoimmune adrenal diseases $(n=84)$, non-adrenal autoimmune diseases $(n=37)$, idiopathic vitiligo $(n=8)$ and 56 healthy blood donors were studied.

Results: Fourteen of twenty-three (61\%) of patients with autoimmune polyglandular syndrome (APS) type I and 1/34 (3\%) of patients with isolated Addison's disease (AD) were positive for TPH Abs. None of the patients with APS type II $(n=27)$, coeliac disease $(n=10)$, autoimmune thyroid disease (AITD) $(n=11)$, type 1 diabetes mellitus (DM) $(n=16)$ or idiopathic vitiligo $(n=8)$ was positive for TPH Abs. AADC Abs were detected in 12/23 (52\%) patients with APS type I, in 1/29 (3\%) patients with APS type II and 1/34 (3\%) patients with isolated AD. None of the patients with coeliac disease, type $1 \mathrm{DM}$, AITD or idiopathic vitiligo was positive for AADC Abs. TPH Abs were found to interact with the C-terminal amino acids (aa) 308-423, central aa 164-205 and N-terminal aa 1-105 of the TPH molecule. AADC Ab binding epitopes were within the C-terminal aa 382-483, the central aa 243-381 and the N-terminal aa $1-167$.

Conclusions: Our study suggests that TPH Abs and AADC Abs react with several different epitopes and that different epitopes are recognized by different sera. The prevalence of TPH Abs and AADC Abs in patients with APS type I in our study is in agreement with previous reports. TPH Abs and AADC Abs were found very rarely in patients with other forms of autoimmune adrenal disease and were not detected in patients with non-adrenal autoimmune diseases.
\end{abstract}

European Journal of Endocrinology 150 313-321

\section{Introduction}

Autoimmune adrenal disease can present as isolated Addison's disease (AD) or as a component of autoimmune polyendocrine syndrome (APS) type I, type II or type IV (1). In addition, some patients may have serological markers of adrenal autoimmunity in the absence of clinical disease and these cases represent potential or subclinical AD (1). APS type I is an autosomal recessive disease and various mutations of the autoimmune regulator (AIRE) gene on chromosome 21q22.3 appear to be associated with this syndrome $(2,3)$. APS type I presents with at least two out of the three main component diseases of APS type I, i.e. $\mathrm{AD}$, hypoparathyroidism and chronic mucocutaneous candidiasis. In addition, patients with APS type I often develop one or more of the following diseases: hypergonadotropic hypogonadism, autoimmune thyroid disease (AITD), type 1 diabetes mellitus (DM), alopecia, vitiligo, chronic hepatitis, chronic atrophic gastritis, pernicious anaemia, malabsorption, keratoconjunctivitis, neoplasias and nail dystrophy. Consequently, various organspecific and/or organ-non-specific autoantibodies (Abs) are detected in sera from patients with APS type I (1). Recently, the relationship between Abs to tryptophan hydroxylase (TPH) with intestinal dysfunction and Abs to aromatic L-amino acid decarboxylase (AADC) with autoimmune hepatitis and vitiligo in patients with APS type I have been reported (4-7). However, the prevalence of TPH Abs and AADC Abs in the patients 
with other forms of AD has not been studied in detail. Consequently we have studied the prevalence of TPH Abs and AADC Abs in the patients with different forms of autoimmune $\mathrm{AD}$ and assessed which epitope regions on TPH and AADC are recognised by Abs.

\section{Materials and methods}

\section{Patients}

Serum samples were obtained from 23 patients with APS type I (13 females and 10 males; mean age 25 years; range 3-64 years), 29 patients with APS type II (23 females and 6 males; mean age 39 years; range 19-64 years) and 34 patients with isolated $\mathrm{AD}$ (18 females and 16 males; mean age 35 years; range $6-78$ years). Sera from patients with non-adrenal autoimmune diseases were also used in the study; 16 sera from patients with type 1 DM all positive for glutamic acid decarboxylase (GAD) Abs (12 females and 4 males; mean age 16 years; range 3-73 years), 11 sera from patients with AITD all positive for thyroid peroxidase Abs and/or thyroglobulin Abs and/or thyrotrophin receptor Abs (10 females and 1 male; mean age 40 years; range 23-61 years) and 10 sera positive for tissue transglutaminase (tTG) Abs from patients with coeliac disease (7 females and 3 males; mean age 40 years; range 15-78 years). In addition, sera from 8 patients with idiopathic vitiligo and 56 healthy blood donors were used in the study. Patients gave informed consent for the study and healthy blood donor sera were purchased from Golden West Biologicals, Vista, CA, USA.

Disease diagnosis in each case was based on typical clinical, immunological and biochemical grounds (1). Patients with APS type I and type II were classified using the criteria for APS as described elsewhere (1). Adrenal cortex Abs (ACA) were detected by the classical indirect immunofluorescence technique using thin cryostatic sections of normal human adrenal glands, and steroid-producing cell Abs (StCA) were detected by a complement-fixing indirect immunofluorescence technique using normal human testis as described previously $(8,9)$. Autoantibodies to steroid 21-hydroxylase (21-OH) were measured using a diagnostic kit based on ${ }^{125}$ I-labelled recombinant human 21-OH (RSR Ltd,
Cardiff, UK) (10). Autoantibodies to steroid $17 \alpha$ hydroxylase $(17 \alpha-\mathrm{OH})$ and to p450 cytochrome side chain cleavage enzyme (p450scc) were detected using an immunoprecipitation assay (IPA) based on ${ }^{35} \mathrm{~S}$ labelled human autoantigens produced in an in vitro TnT rabbit reticulocyte system (Promega UK Ltd, Southampton, Hants, UK) as described previously (11). All other autoantibodies were detected in patient sera using diagnostic kits from RSR Ltd. The disease specificity and sensitivity of the above assays have been described in detail previously $(1,10-17)$.

\section{Preparation of plasmids containing TPH and AADC sequences}

The cDNAs that encoded TPH and AADC (cloned into the psp64-polyA vector) $(5,6)$ were kindly provided by Dr O Kämpe (Uppsala, Sweden).

Full-length TPH cDNA was subcloned into the BamHI site of pTZ18F as described previously (18) and fulllength AADC cDNA was subcloned into the XbaI/BamHI site of the same plasmid. Various deletions of the TPH cDNA (from the $\mathrm{C}$ terminus) and various $\mathrm{C}$-terminal deletions of the AADC cDNA were generated using naturally occurring restriction enzyme sites as shown in Table 1.

\section{Analysis of reactivity of TPH Abs or AADC Abs with full-length and modified TPH or AADC proteins}

Full-length and modified ${ }^{35}$ S-labelled TPH or AADC proteins (Table 1) were produced in the in vitro TnT system (Promega) incorporating ${ }^{35}$ S-methionine (Amersham Biosciences, Chalfont St Giles, Bucks, UK) as described before (19). Proteins synthesised from different constructs were analysed on 12\% SDS-PAGE (20) followed by autoradiography using Fuji medical X-ray film (Genetic Research Instrumentation Ltd, Braintree, Essex, UK).

Binding of TPH Abs or AADC Abs to ${ }^{35}$ S-labelled fulllength and modified respective proteins were assessed using IPAs carried out in multiwell filter plates (Millipore (UK) Ltd, Watford, UK) as described previously $(11,19)$. Briefly, $50 \mu \mathrm{l}$ serum diluted 1:10 in assay buffer $(200 \mathrm{mM} \mathrm{NaCl}, 150 \mathrm{mM}$ Tris, $\mathrm{pH} 8.3$,

Table 1 Summary of modifications of TPH and AADC proteins.

\begin{tabular}{lccccc}
\hline & \multicolumn{2}{c}{ TPH } & & & AADC \\
\cline { 1 - 4 } $\begin{array}{l}\text { Restriction } \\
\text { sites used }\end{array}$ & $\begin{array}{c}\text { Amino acids } \\
\text { deleted }\end{array}$ & $\begin{array}{c}\text { Mol. wt (kDa) } \\
\text { of expressed protein }\end{array}$ & & $\begin{array}{c}\text { Restriction } \\
\text { sites used }\end{array}$ & $\begin{array}{c}\text { Amino acids } \\
\text { deleted }\end{array}$ \\
\hline None & None & 51 & None & None \\
Pstl & $424-444$ & 48.7 & Bbrpl & $382-483$ \\
BstXI & $308-444$ & 35.8 & Blul & $243-483$ \\
EcoRV & $206-444$ & 24 & Pstl & $168-483$ \\
EcoRI & $165-444$ & 18.9 & & 26.5 \\
Styl & $106-444$ & 12 & & 18 \\
\hline
\end{tabular}


$10 \mathrm{mg} / \mathrm{ml}$ bovine serum albumin, $0.5 \mathrm{mg} / \mathrm{ml} \mathrm{NaN}_{3}$ and $1 \%$ Tween 20) was incubated in duplicate with $50 \mu \mathrm{l}$ ${ }^{35}$ S-labelled protein diluted in assay buffer ( $30000 \mathrm{dpm}$ ) for $2 \mathrm{~h}$ at room temperature followed by $1 \mathrm{~h}$ of incubation at room temperature with $50 \mu \mathrm{l}$ Protein A-Sepharose (diluted 1:10 in assay buffer; Amersham Biosciences). The mixtures were then washed by filtration and the ${ }^{35}$ S-labelled immune complexes bound to Protein A-Sepharose were counted in a scintillation $\beta$ counter.

In the case of TPH $\mathrm{Ab}$ and AADC Ab IPAs, the Abpositive reference was a serum from a APS type I patient with high levels of TPH Abs or AADC Abs. The negative reference was serum from an individual healthy blood donor. Results are expressed as antibody index as described (19) using the formula:

[ $\mathrm{dpm}$ in the presence of test serum - d.p.m.

in the presence of negative control)/

(dpm in the presence of positive control - d.p.m.

in the presence of negative control) $] \times 100$

Autoantibody binding to each modified protein was assessed in two separate experiments (each in duplicate). Results are expressed as \% Ab binding to modified protein relative to the binding to full-length protein using the formula:

[(binding of test sample to modified ${ }^{35} \mathrm{~S}$-TPH or $\left.{ }^{35} \mathrm{~S}-\mathrm{AADC}\right) /($ binding of test sample to full length

${ }^{35} \mathrm{~S}-\mathrm{TPH}\left(\right.$ or $\left.\left.{ }^{35} \mathrm{~S}-\mathrm{AADC}\right)\right] \times 100$

The difference between mean binding of test samples to the modified protein relative to the full-length protein was assessed using Wilcoxon's matched pairs test. In addition, the difference in mean binding of test samples to different modified proteins was compared using Wilcoxon's matched pairs test.

\section{Results}

\section{Expression of full-length and modified TPH or AADC in the TnT system}

Full-length and modified recombinant TPH or AADC proteins produced in the TnT system were analysed by SDS-PAGE and autoradiography (data not shown). In the case of TPH proteins, ${ }^{35}$ S-labelled products of the expected molecular weights (from $51 \mathrm{kDa}$ to $12 \mathrm{kDa}$ ) were obtained from the respective constructs (Table 1 ). In the case of AADC proteins, ${ }^{35}$ S-labelled products of the expected molecular weights (between $54 \mathrm{kDa}$ and $18 \mathrm{kDa}$ ) were also obtained (Table 1 ).

\section{Immunoprecipitation assays}

APS type I sera with high levels of TPH Abs immunoprecipitated up to about $35 \%$ of the ${ }^{35}$ S-labelled fulllength TPH preparation. Sera from healthy blood donors precipitated $0.73 \pm 0.24 \%$ of this ${ }^{35}$ S-labelled TPH (mean \pm S.D.; range $0.5-1.8 \% ; n=56$ ). Interassay coefficient of variation (C.V.) for a sample with high levels of $\mathrm{TPH} \mathrm{Ab}\left(31.5 \pm 1.3 \%\right.$ of ${ }^{35} \mathrm{~S}-\mathrm{TPH}$ binding; mean \pm S.D. $)$ was $4.2 \%(n=5)$ and for a sample with medium TPH Ab level (19.1 $\pm 0.9 \%$ binding; means \pm S.D.) it was $4.8 \%(n=5)$. The intra-assay C.V. for a sample with high levels of TPH Ab $(30.4 \pm 1.1 \%$ binding; mean \pm S.D. $)$ was $3.6 \%(n=10)$ and for a sample with medium levels of $\mathrm{TPH}$ Ab (18.2 $\pm 1.0 \%$ binding; mean \pm S.D. $)$ it was $5.7 \%(n=10)$. The limit of detection in the ${ }^{35}$ S-labelled TPH IPA was estimated as an index value of 2.3 based on the mean +3 S.D. of the TPH $\mathrm{Ab}$ indexes obtained from individual healthy blood donor sera $(n=56)$ (Fig. 1A). 14/23 (61\%) of patients with APS type I were positive for TPH Abs (index values from 8.0 to 100), none of 27 APS type II patients tested was positive and $1 / 34(3 \%)$ of patients with isolated AD was positive for TPH Abs (low index value of 4.0). None of 10 patients with coeliac disease, none of 16 patients with type $1 \mathrm{DM}$, none of 11 patients with AITD and none of 8 patients with idiopathic vitiligo was positive for TPH Abs (Fig. 1A).

APS type I sera with high levels of AADC Abs immunoprecipitated up to about $60 \%$ of the ${ }^{35}$ S-labelled fulllength AADC preparation. Sera from healthy blood donors precipitated $2.9 \pm 0.5 \%$ of the ${ }^{35}$ S-labelled AADC (mean \pm S.D.; range $2.1-3.9 \% ; n=56$ ). The inter-assay C.V. for a sample with high levels of AADC Abs $\quad\left(53.0 \pm 5.2 \%\right.$ of ${ }^{35}$ S-labelled AADC binding; mean \pm S.D. $)$ was $9.8 \%(n=5)$ and a C.V. of $15.9 \%$ $(n=5)$ was found for a sample with medium level of Abs $(26.3 \pm 4.2 \%$ binding; mean \pm s.D. $)$. The intraassay C.V. for a sample with high level of Abs (56.6 $\pm 3.8 \%$ binding; mean \pm S.D.) was $6.7 \%(n=7)$ and $4.3 \%(n=8)$ for a sample with medium levels of Abs $(27.3 \pm 1.2 \%$ binding; mean \pm S.D. $)$. The limit of detection in the ${ }^{35}$ S-labelled AADC IPA was estimated as an index value of 2.7 based on the mean +3 s.D. of the AADC antibody indexes obtained from 56 individual healthy blood donor sera (Fig. 1B). 12/23 (52\%) of patients with APS type I were positive for AADC Abs (index value from 2.8 to 125), 1/29 (3\%) APS type II patients was positive for AADC Abs (index of 10.1) and $1 / 34(3 \%)$ of patients with isolated $\mathrm{AD}$ was positive for AADC Abs (index of 9.3). However, none of the 10 patients with coeliac disease, 16 patients with type 1 DM, 11 patients with AITD or 8 patients with idiopathic vitiligo was positive for AADC Abs (Fig. 1B).

Detailed clinical and autoantibody information on the patients with APS type I, APS type II and isolated $\mathrm{AD}$ who were found positive for TPH Abs and/or AADC Abs are shown in Table 2. Eleven patients (10 with APS type I and 1 with AD) were positive for both TPH Abs and AADC Abs, 4 patients (all with APS type I) were positive for TPH Abs only and 3 patients ( 2 with APS type I and 1 with APS type II) for AADC Abs only. 
(A)

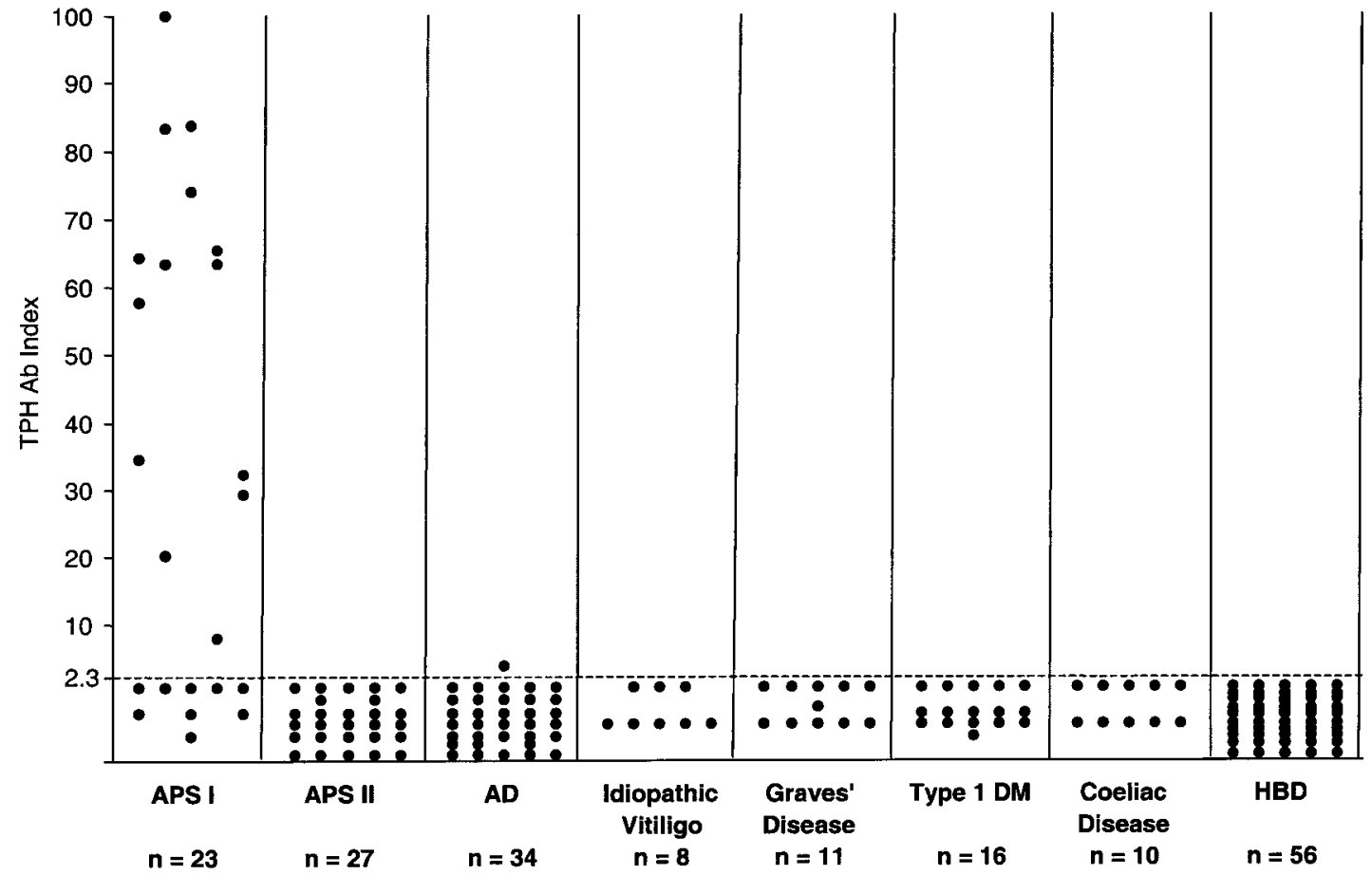

(B)

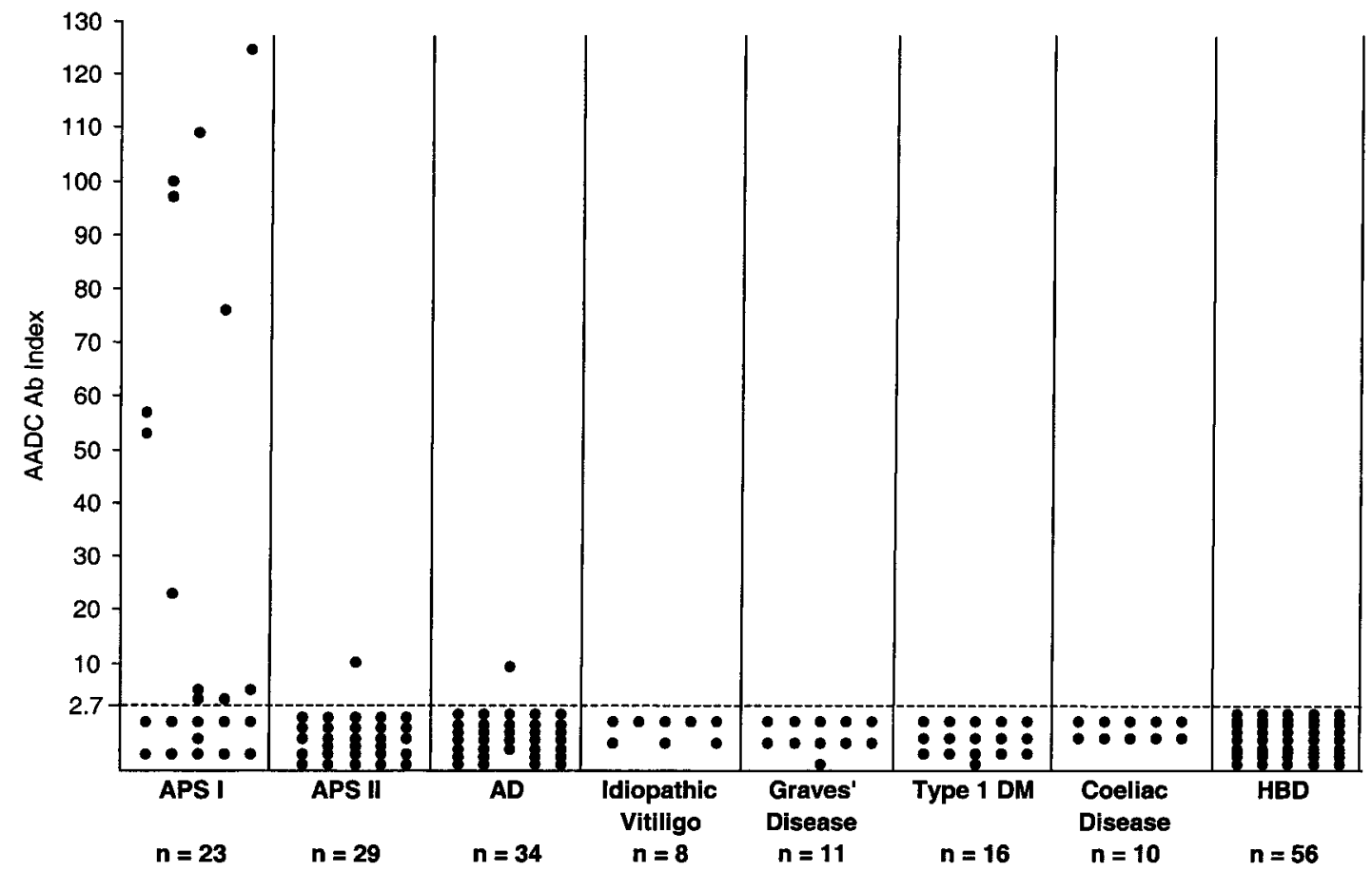

Figure 1 Autoantibodies to (A) TPH and (B) AADC by IPAs in different patient groups. The broken lines show the cut-off points for positivity. This was determined as the mean+3 S.D. of the index values obtained with the 56 healthy blood donors (HBD) sera. 
Table 2 Clinical and Ab characteristics of patients with APS I, APS II and isolated AD positive for TPH and/or AADC Abs.

\begin{tabular}{|c|c|c|c|c|c|c|c|c|c|c|}
\hline $\begin{array}{l}\text { Patient } \\
\text { no. }\end{array}$ & $\begin{array}{c}\text { Age } \\
\text { (years) }\end{array}$ & Sex & Disease & $\begin{array}{c}\text { TPH } \mathbf{A b}^{1} \\
\text { index }\end{array}$ & $\begin{array}{c}\text { AADC } A b^{2} \\
\text { index }\end{array}$ & $\begin{array}{c}\text { 21-OH } \mathbf{A b}^{3} \\
\text { (units/ml) }\end{array}$ & ACA & $\begin{array}{c}17 \alpha-\mathrm{OH} \mathbf{A b}^{4} \\
\text { (units/ml) }\end{array}$ & $\begin{array}{l}\text { P450scc } \mathbf{A b}^{5} \\
\text { (units } / \mathrm{ml} \text { ) }\end{array}$ & StCA \\
\hline 1 & 8 & $M$ & $\begin{array}{l}\text { APS type I; AD, C, } \\
\text { HPT, RhA }\end{array}$ & 64.2 & 53 & 92 & + & Neg & 8.9 & Neg \\
\hline 2 & 31 & $\mathrm{~F}$ & $\begin{array}{l}\text { APS type I; AD, C, HPT, POF, } \\
\text { A, HT }\end{array}$ & 34.6 & 57 & 1.7 & + & $>64$ & $>32$ & + \\
\hline 3 & 28 & $\mathrm{~F}$ & $\begin{array}{l}\text { APS type I; AD, C, HPT, POF, } \\
\text { A, AG, PA, Ch }\end{array}$ & 57.7 & 5 & $\mathrm{Neg}$ & + & $>64$ & 4 & + \\
\hline 4 & 47 & $F$ & $\begin{array}{l}\text { APS type I; AD, C, HPT, POF, } \\
\text { PA, Sj, Ca, PN }\end{array}$ & 29.3 & Neg & 268.3 & + & $\mathrm{Neg}$ & 19.9 & + \\
\hline 5 & 10 & M & $\begin{array}{l}\text { APS type I; AD, C, HPT, } \\
\text { A, V, Ma }\end{array}$ & 63.3 & 23 & 1.5 & + & Neg & 4 & + \\
\hline 6 & 15 & M & $\begin{array}{l}\text { APS type I; AD, C, HPT, } \\
\text { A, V, Ma, HT }\end{array}$ & 100 & 97.1 & Neg & $\mathrm{Neg}$ & Neg & $\mathrm{Neg}$ & Neg \\
\hline 7 & 36 & $\mathrm{~F}$ & $\begin{array}{l}\text { APS type I; AD, C, HPT, } \\
\text { CD, POF, As }\end{array}$ & 20.3 & Neg & 32.3 & + & $>64$ & 20 & + \\
\hline 8 & 5 & M & $\begin{array}{l}\text { APS type I; AD, C, HPT, } \\
\text { A, HT, Ma }\end{array}$ & 83.2 & 5 & 51 & + & Neg & $>32$ & + \\
\hline 9 & 9 & M & $\begin{array}{l}\text { APS type I; C, HPT, } \\
\text { Ma, A, DM }\end{array}$ & 74 & Neg & 61.3 & + & 6 & Neg & + \\
\hline 10 & 33 & $M$ & $\begin{array}{l}\text { APS type I; AD, C, } \\
\text { HPT, V, Ma }\end{array}$ & 83.8 & 76 & 2.5 & + & $>64$ & $\mathrm{Neg}$ & + \\
\hline 11 & 12 & $\mathrm{~F}$ & $\begin{array}{l}\text { APS type I; AD, C, } \\
\text { HPT, HT, Sj }\end{array}$ & 63.4 & 109 & 44.5 & + & 12.9 & $\mathrm{Neg}$ & + \\
\hline 12 & 5 & $\mathrm{~F}$ & APS type I; AD, HPT & 65.4 & 124.6 & 6.4 & + & Neg & Neg & Neg \\
\hline 13 & 20 & $\mathrm{~F}$ & APS type I; AD, HPT, C & 8.0 & 3.4 & 7.5 & + & 29.6 & & + \\
\hline 14 & 20 & $\mathrm{~F}$ & APS type I; AD, HPT & 32.2 & Neg & 20.1 & + & $>64$ & $>32$ & + \\
\hline 15 & 47 & $\mathrm{~F}$ & $\begin{array}{l}\text { APS type I; AD, HPT, C, A, } \\
\mathrm{Ca}, \mathrm{Sj}, \mathrm{TS}\end{array}$ & Neg & 100 & $\mathrm{Neg}$ & Neg & $\mathrm{Neg}$ & $\mathrm{Neg}$ & Neg \\
\hline 16 & 8 & $\mathrm{~F}$ & APS type I; AD, HPT & Neg & 2.8 & 36.5 & + & Neg & 4.6 & + \\
\hline 17 & 32 & M & $A D, A$ & 4.0 & 9.3 & 1710 & + & Neg & Neg & $\mathrm{Neg}$ \\
\hline 18 & 44 & $\mathrm{~F}$ & APS type II; AD, GD & Neg & 10.1 & 45.8 & + & $\mathrm{Neg}$ & 2.4 & Neg \\
\hline
\end{tabular}

${ }^{1}$ Index values $>2.3$ are positive; ${ }^{2}$ index values $>2.7$ are positive; ${ }^{3}$ values $>1.0$ units $/ \mathrm{ml}$ are positive; ${ }^{4}$ values $>1.0$ units $/ \mathrm{ml}$ are positive; ${ }^{5}$ values $>1.0$ units $/ \mathrm{ml}$ are positive.

A, alopecia; AG, atrophic gastritis; AS, aspleria; C, candidiasi; Ca, cancer; Ch, cholelitiasis; CD, coeliac disease; GD, Graves' disease; HPT, hypoparathyrodism; HT, hepatitis; Ma, malabsorption; PA, pernicious anaemia; PN, peripheral neuropathy; POF, premature ovarian failure; RhA, rheumatoid arthritis; Sj, Sjogren's syndrome; TS, Turner's syndrome; V, vitiligo; Neg, negative.

In addition, 19/23 (83\%) APS type I patients were positive for 21-OH Abs and 15/23 (65\%) were positive for $17 \alpha-\mathrm{OH}$ Abs and/or p450scc Abs (Table 2). Furthermore, 5/23 (22\%) were positive for tTG Abs and 9/23 (40\%) were positive for GAD Abs (data not shown).

\section{Antibody binding to modified TPH}

Binding of TPH Abs from 11 different sera to full-length and modified TPH proteins is shown in Table 3. When the last C-terminal 21 amino acids were deleted (i.e. aa $1-423)$ there was little or no effect on mean TPH $\mathrm{Ab}$ binding relative to full-length TPH $(P=0.168)$. In contrast, more extensive $\mathrm{C}$-terminal deletions reduced $\mathrm{TPH} \mathrm{Ab}$ binding in all sera studied. In particular, TPH truncation at aa 307 (i.e. aa 1-307 expressed) resulted in reduction in TPH $\mathrm{Ab}$ binding relative to full-length (mean $48 \pm 28 \%$; range $4-71 \%$; $P<0.01$ ). In the case of TPH with aa 1-205 expressed, the mean

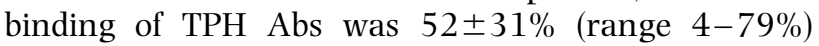
relative to full-length $(P<0.01)$. More extensive C-terminal deletions (i.e. aa expressed 1-164) resulted in further changes in TPH Ab binding with mean binding relative to full-length of $37 \pm 22 \%$ (range $3-68 \%$ ) $(P<0.01)$. Deletion of a further 59 amino acids (aa 1-105 expressed) did not cause further changes

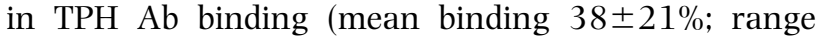
$3-63 \% ; P<0.01$ relative to full-length) (Table 3 ). Sera $(n=2)$ from patients with APS type I that were negative for TPH Abs in IPA using the full-length ${ }^{35}$ S-labelled TPH did not immunoprecipitate any of the modified ${ }^{35}$ S-labelled TPH proteins (data not shown).

In terms of the effect of different TPH amino acid deletions on TPH $\mathrm{Ab}$ binding relative to each other, truncation at aa 307 had a marked effect compared with truncation at aa 423 (aa 1-423 expressed vs aa $1-307$ expressed $P<0.01$ ) and a further deletion of 87 amino acids had an effect compared with truncation at aa 307 (aa 1-307 expressed vs aa 1-205 expressed $P<0.01$ ). When TPH with aa $1-164$ expressed was studied, the TPH Ab binding was reduced even further (aa 1-205 expressed vs aa 1-164 expressed $P=0.01)$ and this effect was not changed when a further 59 amino acids were deleted (aa 1-164 expressed vs aa $1-105$ expressed $P=0.720$ ) (Table 3 ). 
Table 3 Binding of TPH Ab in 11 APS type I sera to intact and modified TPH.

\begin{tabular}{|c|c|c|c|c|c|c|c|}
\hline \multirow[b]{3}{*}{$\begin{array}{l}\text { Serum } \\
\text { no. }\end{array}$} & \multirow[b]{3}{*}{$\begin{array}{r}\text { Relative TPH Ab level in IPA } \\
\text { using full-length }{ }^{35} \mathrm{~S}-\mathrm{TPH}^{1}\end{array}$} & \multicolumn{6}{|c|}{$\frac{\text { Binding of serum to modified }{ }^{35} \mathrm{~S}-\mathrm{TPH}}{\text { Binding of serum to full-length }{ }^{35} \mathrm{~S}-\mathrm{TPH}} \times 100$} \\
\hline & & \multirow[b]{2}{*}{$\begin{array}{l}\text { Full length } \\
(1-444)\end{array}$} & \multicolumn{5}{|c|}{ C-terminal deletions } \\
\hline & & & $\begin{array}{c}1-423 \\
\text { expressed }\end{array}$ & $\begin{array}{l}1-307 \\
\text { expressed }\end{array}$ & $\begin{array}{c}1-205 \\
\text { expressed }\end{array}$ & $\begin{array}{c}1-164 \\
\text { expressed }\end{array}$ & $\begin{array}{l}1-105 \\
\text { expressed }\end{array}$ \\
\hline 1 & 100 & 100 & 100 & 63 & 69 & 49 & 47 \\
\hline 2 & 68 & 100 & 87 & 4 & 4 & 3 & 3 \\
\hline 3 & 78 & 100 & 111 & 68 & 75 & 68 & 63 \\
\hline 4 & 63 & 100 & 91 & 6 & 5 & 5 & 8 \\
\hline 5 & 86 & 100 & 91 & 72 & 79 & 52 & 58 \\
\hline 6 & 114 & 100 & 95 & 71 & 75 & 52 & 47 \\
\hline 7 & 49 & 100 & 99 & 30 & 33 & 26 & 35 \\
\hline 8 & 97 & 100 & 105 & 66 & 72 & 48 & 52 \\
\hline 9 & 13 & 100 & 80 & 14 & 16 & 10 & 14 \\
\hline 10 & 117 & 100 & 101 & 71 & 79 & 49 & 44 \\
\hline 11 & 107 & 100 & 96 & 65 & 69 & 50 & 49 \\
\hline Mean & & 100 & 96 & 48 & 52 & 37 & 38 \\
\hline $\begin{array}{l}\text { S.D. } \\
P^{2}\end{array}$ & & 0 & $P=0.168$ & $P<0.01$ & $\begin{array}{c}31 \\
P<0.01\end{array}$ & $P<0.01$ & $\begin{array}{c}21 \\
P<0.01\end{array}$ \\
\hline$P^{3}$ & & & & & & $P=$ & 720 \\
\hline$P^{3}$ & & & & & & 01 & \\
\hline$P^{3}$ & & & & & & & \\
\hline$P^{3}$ & & & & .01 & & & \\
\hline
\end{tabular}

${ }^{1} 23-39 \%$ of ${ }^{35} \mathrm{~S}$-full-length TPH bound to serum 1 in these experiments and the results shown for sera 2 to 11 are relative to serum 1 binding; healthy blood donor sera bound $0.7-1.8 \%$ of ${ }^{35} \mathrm{~S}$-full-length TPH.

${ }^{2} P$ values shown are for the difference between TPH Ab binding to full-length and modified ${ }^{35} \mathrm{~S}-\mathrm{TPH}$.

${ }^{3} \mathrm{P}$ values shown are for the difference between TPH Ab binding to differently modified ${ }^{35} \mathrm{~S}-\mathrm{TPH}$.

\section{Autoantibody binding to modified AADC}

AADC Ab binding to full-length and modified AADC proteins in 10 patients studied is shown in Table 4. When the C-terminal 102 amino acids were deleted (aa 1-381 expressed) there was no effect on mean
AADC $\mathrm{Ab}$ binding relative to full-length (mean $84 \pm 27 \%$; range $30-110 ; P=0.176$ ). However, the effect on individual sera varied, in the case of three sera the ability to bind AADC with the C-terminal 102 amino acids missing was reduced (range $30-55 \%$ relative to full-length) whereas in the case

Table 4 Binding of AADC Ab in ten APS type I sera to intact and modified AADC.

\begin{tabular}{|c|c|c|c|c|c|}
\hline \multirow[b]{3}{*}{ Serum no. } & \multirow{3}{*}{$\begin{array}{l}\text { Relative AADC Ab level in IPA } \\
\text { using full-length }{ }^{35} \mathrm{~S}^{-A A D C}{ }^{1}\end{array}$} & \multicolumn{4}{|c|}{$\frac{\text { Binding of serum to modified }{ }^{35} \text { S-AADC }}{\text { Binding of serum to full-length }{ }^{35} \text { S-AADC }} \times 100$} \\
\hline & & \multirow[b]{2}{*}{ Full length (1-483) } & \multicolumn{3}{|c|}{ C-terminal deletions } \\
\hline & & & 1-381 expressed & 1-242 expressed & 1-167 expressed \\
\hline 1 & 100 & 100 & 100 & 61 & 9 \\
\hline 2 & 99 & 100 & 104 & 74 & 20 \\
\hline 3 & 65 & 100 & 30 & 4 & 10 \\
\hline 4 & 96 & 100 & 104 & 36 & 20 \\
\hline 5 & 66 & 100 & 55 & 4 & 6 \\
\hline 6 & 77 & 100 & 58 & 4 & 14 \\
\hline 7 & 104 & 100 & 100 & 50 & 23 \\
\hline 8 & 80 & 100 & 100 & 13 & 5 \\
\hline 9 & 72 & 100 & 110 & 38 & 6 \\
\hline 10 & 14 & 100 & 83 & 13 & 30 \\
\hline Mean & & 100 & 84 & 30 & 14 \\
\hline S.D. & & 0 & $\begin{array}{c}27 \\
P=0.176\end{array}$ & $P<0.01$ & $P<{ }^{8} 0.01$ \\
\hline$P^{3}$ & & \multirow{2}{*}{\multicolumn{4}{|c|}{$P<0.01$}} \\
\hline$P^{3}$ & & & & & \\
\hline
\end{tabular}

${ }^{1} 45-46 \%$ of ${ }^{35}$ S-full-length AADC bound to serum 1 in these experiments and the results shown for sera 2 to 10 are relative to serum 1 binding; healthy blood donor sera bound $2.5-2.6 \%$ of ${ }^{35}$ S-full-length AADC.

${ }^{2} P$ values shown are for the difference between AADC Ab binding to full-length and modified ${ }^{35} \mathrm{~S}-\mathrm{AADC}$.

${ }^{3} P$ values shown are for the difference between AADC Ab binding to differently modified ${ }^{35} \mathrm{~S}$-AADC. 
of seven sera the binding was affected little or not at all (range 83-110\%). In contrast, truncation at aa 242 (aa 1-242 expressed) had a marked effect on mean $\mathrm{AADC} \mathrm{Ab}$ binding $(30 \pm 26 \%$; range $4-74 \%$; $P<0.01$ compared with full-length). Further C-terminal amino acid deletions (i.e. aa 1-167 expressed) had a clear effect on AADC Ab binding in all sera studied with a mean binding relative to full-length of $14 \pm 8 \%$; range $5-30 \% ; P<0.01$. Sera $(n=2)$ from patients with APS type I that were negative for AADC Abs in IPA using the full-length ${ }^{35}$ S-labelled AADC did not immunoprecipitate any of the modified ${ }^{35} \mathrm{~S}-$ labelled AADC proteins (data not shown).

In terms of the effect of different modifications in relation to each other, truncation at aa 242 had a marked effect on AADC Ab binding compared with truncation at aa 381 (aa 1-382 expressed vs aa $1-242$ expressed $P<0.01$ ) but a further deletion (aa 1-167 expressed) had no effect on AADC Ab binding compared with truncation at aa 242 (aa $1-242$ expressed vs aa $1-167$ expressed $P=0.139$ ).

\section{Discussion}

In our study, TPH Abs and AADC Abs were found in a majority of patients with APS type I (61 and 52\% respectively). In contrast, only $1 / 29$ patients $(3 \%)$ with APS type II was positive for AADC Abs and $1 / 34$ patients $(3 \%)$ with isolated $\mathrm{AD}$ was positive for both TPH and AADC Abs. Previous studies have reported that $38 / 80(48 \%)$ of APS type I patients were positive for TPH Abs (6) and 35/69 (51\%) of APS type I patients positive for AADC Abs (5).

The prevalence of malabsorption among the patients with APS type I has been reported to vary from 6 to $22 \%$ (1). In our study, 5 out of $23(22 \%)$ APS type I patients presented with malabsorption and all 5 patients were positive for TPH Abs (Table 2). However, 9/18 (50\%) APS type I patients without malabsorption were also positive for TPH Abs. This can be compared with a previous study in which $17 / 19$ (89\%) APS type I patients with gastrointestinal symptoms were positive for TPH Abs as well as 21/61 (34\%) APS type I patients without gastrointestinal symptoms (6).

Vitiligo and chronic active hepatitis in APS type I have been reported to occur in $8-25 \%$ and $5-31 \%$ of patients respectively (1). Of the APS type I patients with vitiligo and/or chronic active hepatitis, 6/8 (75\%) were positive for AADC Abs in our study. However, 6/15 (40\%) APS type I patients without vitiligo and/or chronic active hepatitis were also positive for AADC Abs. Husebye et al. (5) have reported that $11 / 12(92 \%)$ APS type I patients with hepatitis were positive for AADC Abs; however, 24/57 (42\%) of their patients without hepatitis were also positive for AADC Abs. In the same study, 12/15 (80\%) APS type I patients with vitiligo had AADC Abs compared with $23 / 54(43 \%)$ of APS type I patients without vitiligo
(5). None of the 8 patients with idiopathic vitiligo we have studied was positive for AADC Abs.

Our studies and those of others (6) have shown that TPH Abs are detected in a higher proportion of patients with malabsorption but are also present in those without malabsorption. In addition, the prevalence of AADC Abs is higher in patients with vitiligo and/or hepatitis but also a considerable proportion (about 40\%) of patients without these diseases are AADC Ab positive (5). These observations suggest that the disease specificity of TPH Abs for malabsorption in APS type I and disease specificity of AADC Abs for vitiligo and/or hepatitis requires further investigation.

In our study, a large proportion of APS type I patients were positive for Abs to $21-\mathrm{OH}(83 \%), 17 \alpha-\mathrm{OH}$ and/or p450scc (65\%) (Table 2). Furthermore, $40 \%$ of patients had detectable GAD Abs but did not have type 1 DM. In addition, some patients $(n=5)$ were positive for $\operatorname{IgA}$ tTG Abs (22\%) (16) but none had coeliac disease. Three of these patients had normal duodenal biopsy results while 2 other patients did not undergo the biopsy.

Thus, the majority of APS type I patients had more than four different autoantibodies. This is consistent with the well-known presence of multiple autoantibodies, sometimes in the absence of clinical disease, in sera from APS type I patients $(1,21-23)$.

Mutations in the AIRE gene are associated with APS type I $(2,3,24)$ but no relationship between mutations in the AIRE gene and the ability to produce autoantibodies in patients without APS type I (for example Graves' disease or Hashimoto's thyroiditis) has been found (25). In our study, TPH Abs and AADC Abs were detected almost exclusively in patients with APS type I. The APS type II and AD patients who were positive for these autoantibodies may have had a mutation in the AIRE gene and represented an unidentified or atypical APS type I $(24,26,27)$. However, we were unable to carry out analysis of the AIRE gene in these two patients.

TPH is a member of the biopterin-dependent hydroxylases family (1) together with tyrosine hydroxylase (TH) and phenylalanine hydroxylase (PAH) and autoantibodies to TH and PAH have been described in patients with APS type I (28). In addition, autoantibodies to histidine decarboxylase, a histamine-synthesising enzyme that is pyridoxal phosphate dependent have been reported very recently in patients with APS type I $(29,30)$. Other known targets of autoimmune response in patients with APS type I such as GAD and AADC are also pyridoxal phosphate-dependent enzymes. The reasons why the autoimmune responses in APS type I involve particularly the enzymes important for the biosynthesis of neurotransmitters is not clear at present $(1,28-30)$.

In our study, a series of modified TPH and AADC proteins labelled with ${ }^{35} \mathrm{~S}$ was used to analyse autoantibody epitopes. At least three regions on the TPH 
molecule were found to be involved in the interaction with TPH Abs: the C-terminal region aa 308-423, central region aa 164-205 and N-terminal region aa 1-105. The varying effects of different modifications of the TPH molecule on TPH Ab binding in different patients suggested that TPH Abs in patient sera recognise multiple epitopes. At least some of the TPH Ab binding sites were located or were dependent on the amino acids within the catalytic domain of TPH (aa 308-444) and an inhibiting effect of TPH Abs on TPH enzyme activity has been reported previously (28). In the case of two patients, however, the TPH $\mathrm{Ab}$ epitope(s) appeared to be located only within the C-terminal region (aa 292-423) (Table 3; sera nos 2 and 4).

In the case of AADC, the amino acids involved in the $\mathrm{AADC} \mathrm{Ab}$ binding were located in different parts of the molecule including the $\mathrm{C}$-terminal region of aa 382-483, the middle region (aa 243-381) and the $\mathrm{N}$-terminal region (aa 1-167). AADC Abs in patient sera appeared to be directed to at least two different regions except for one serum (Table 4, no. 10) that appeared to react principally with an epitope(s) dependent on aa $242-381$.

Husebye et al. (31) have reported that AADC Abs in patient sera can inhibit AADC activity in vitro and that different sera have different inhibiting effects, suggesting a heterogeneity of autoantibody binding sites and this is in agreement with the observations reported here. Furthermore, the relationship between the domains important for enzyme activity and domains involved in autoantibody binding has been demonstrated in the case of other autoantibodies reactive with the enzymes $(32,33)$.

Our experiments with modified TPH and AADC proteins showed that different stretches of amino acids covering almost the entire sequence of the molecules were important for autoantibody binding in the case of both antigens. Involvement of long and different stretches of amino acids in the autoantibody binding is a known feature of conformational binding sites (34). It is possible therefore, that the TPH Ab and AADC $\mathrm{Ab}$ binding sites are conformational; i.e. are formed by three dimensional folding of the molecule. Alternatively, the involvement of long stretches of amino acids in autoantibody binding may be related to epitope spreading processes $(32,35)$. Furthermore, the different binding pattern of TPH Abs and AADC Abs to modified respective antigens in different patient sera suggested heterogeneity of the autoantibodies in terms of the epitope recognition.

Overall, our study on the prevalence of TPH Abs and AADC Abs in sera from patients with APS type I is in agreement with previous reports $(5,6)$. In addition, we have shown that TPH Abs and AADC Abs are present infrequently in the sera from patients with adrenal autoimmune diseases other than APS type I. In the case of patients with these other forms of autoimmune adrenal disease who were positive for TPH Abs or AADC Abs, testing for AIRE gene mutations may be helpful in improving the disease diagnosis $(24,26,27)$.

\section{Acknowledgements}

We thank Dr Olle Kämpe of Uppsala University, Sweden for providing the cDNAs coding for TPH and AADC and Carol James for preparation of the manuscript. C D P was in receipt of a fellowship from RSR Ltd.

\section{References}

1 Betterle C, Dal Pra C, Mantero F \& Zanchetta R. Autoimmune adrenal insufficiency and autoimmune polyendocrine syndromes: autoantibodies, autoantigens, and their applicability in diagnosis and disease prediction. Endocrine Reviews 200223 327-364.

2 Heino M, Peterson P, Kudoh J, Shimizu N, Antonarakis SE, Scott HS et al. APECED mutations in the autoimmune regulator (AIRE) gene. Human Mutation 200118 205-211.

3 Meyer G \& Badenhoop K. Autoimmune regulator (AIRE) gene on chromosome 21: implications for autoimmune polyendocrinopathy-candidiasis-ectodermal dystrophy (APECED) and more common manifestations of endocrine autoimmunity. Journal of Endocrinological Investigation 200225 804-811.

4 Gebre-Medhin G, Husebye ES, Gustafsson J, Winqvist O, Goksøyr A, Rorsman F et al. Cytochrome P450IA2 and aromatic L-amino acid decarboxylase are hepatic autoantigens in autoimmune polyendocrine syndrome type I. FEBS Letters 1997 $412439-445$.

5 Husebye ES, Gebre-Medhin G, Tuomi T, Perheentupa J, Landin-Olsson M, Gustafsson J et al. Autoantibodies against aromatic L-amino acid decarboxylase in autoimmune polyendocrine syndrome type I. Journal of Clinical Endocrinology and Metabolism $199782147-150$.

6 Ekwall O, Hedstrand H, Grimelius L, Haavik J, Perheentupa J, Gustafsson J et al. Identification of tryptophan hydroxylase as an intestinal autoantigen. Lancet $1998 \mathbf{3 5 2} 279-283$.

7 Ekwall O, Sjöberg K, Mirakian R, Rorsman F \& Kämpe O. Tryptophan hydroxylase autoantibodies and intestinal disease in autoimmune polyendocrine syndrome type 1. Lancet $19993 \mathbf{3 4} 568$.

8 Betterle C, Scalici C, Presotto F, Pedini B, Moro L, Rigon F et al. The natural history of adrenal function in autoimmune patients with adrenal autoantibodies. Journal of Endocrinology $1988 \mathbf{1 1 7}$ $467-475$.

9 Betterle C, Rossi A, Dalla Pria S, Artifoni A, Pedini B, Gavasso S et al. Premature ovarian failure: autoimmunity and natural history. Clinical Endocrinology $19933935-43$.

10 Tanaka H, Perez MS, Powell M, Sanders JF, Sawicka J, Chen S et al. Steroid 21-hydroxylase autoantibodies: measurements with a new immunoprecipitation assay. Journal of Clinical Endocrinology and Metabolism 199782 1440-1446.

11 Chen S, Sawicka J, Betterle C, Powell M, Prentice L, Volpato M et al. Autoantibodies to steroidogenic enzymes in autoimmune polyglandular syndrome, Addison's disease, and premature ovarian failure. Journal of Clinical Endocrinology and Metabolism 199681 1871-1876.

12 Southgate K, Creagh FM, Teece M, Kingswood C \& Rees Smith B. A receptor assay for the measurement of TSH receptor antibodies in unextracted serum. Clinical Endocrinology 198420 539-543.

13 Beever K, Bradbury J, Phillips D, McLachlan SM, Pegg C, Goral A et al. Highly sensitive assays of autoantibodies to thyroglobulin and to thyroid peroxidase. Clinical Chemistry $1989 \quad 35$ 1949-1954.

14 Powell M, Prentice L, Asawa T, Kato R, Sawicka J, Tanaka H et al. Glutamic acid decarboxylase autoantibody assay using 
${ }^{125}$ I-labelled recombinant $\mathrm{GAD}_{65}$ produced in yeast. Clinica Chimica Acta $1996256175-188$.

15 Betterle C, Volpato M, Pedini B, Chen S, Rees Smith B \& Furmaniak J. Adrenal-cortex autoantibodies and steroid-producing cell autoantibodies in patients with Addison's disease: comparison of immunofluorescence and immunoprecipitation assays. Journal of Clinical Endocrinology and Metabolism $1999 \mathbf{8 4}$ 618-622.

16 Nakachi K, Swift G, Wilmot D, Chapman C, Baker S, Powell M et al. Antibodies to tissue transglutaminase: comparison of ELISA and immunoprecipitation assay in the presence and in the absence of calcium ions. Clinica Chimica Acta $2001 \mathbf{3 0 4}$ 75-84.

17 Dal Pra C, Chen S, Furmaniak J, Rees Smith B, Pedini B, Moscon A et al. Autoantibodies to steroidogenic enzymes in patients with premature ovarian failure with and without Addison's disease. European Journal of Endocrinology 2003148 565-570.

18 Grennan Jones F, Ziemnicka K, Sanders J, Wolstenholme A, Fiera R, Furmaniak J et al. Analysis of autoantibody epitopes on human thyroid peroxidase. Autoimmunity 199930 157-169.

19 Colls J, Betterle C, Volpato M, Prentice L, Rees Smith B \& Furmaniak J. Immunoprecipitation assay for autoantibodies to steroid 21-hydroxylase in autoimmune adrenal diseases. Clinical Chemistry 199541 375-380.

20 Laemmli UK. Cleavage of structural proteins during the assembly of the head of bacteriophage T4. Nature $1970 \mathbf{2 2 7} 680-684$.

21 Perniola R, Falorni A, Clemente MG, Forini F, Accogli E \& Lobreglio G. Organ-specific and non-organ-specific autoantibodies in children and young adults with autoimmune polyendocrinopathy-candidiasis-ectodermal dystrophy (APECED). European Journal of Encdocrinology $2000 \mathbf{1 4 3} 497-503$.

22 Myhre A-G, Halonen M, Eskelin P, Ekwall O, Hedstrand H, Rorsman $\mathrm{F}$ et al. Autoimmune polyendocrine syndrome type 1 (APS I) in Norway. Clinical Endocrinology 200154 211-217.

23 Cihakova D, Trebusak K, Heino M, Fadeyev V, Tiulpakov A, Battelino T et al. Novel AIRE mutations and P450 cytochrome autoantibodies in Central and Eastern European patients with APECED. Human Mutation 200118 225-232.

24 Halonen M, Eskelin P, Myhre A-G, Perheentupa J, Husebye ES, Kämpe $\mathrm{O}$ et al. AIRE mutations and human leukocyte antigen genotypes as determinants of the autoimmune polyendocrinopathy-candidiasis-ectodermal dystrophy phenotype. Journal of Clinical Endocrinology and Metabolism $2002872568-2574$.

25 Meyer G, Donner H, Herwig J, Böhles H, Usadel KH \& Badenhoop K. Screening for an AIRE-1 mutation in patients with Addison's disease, type 1 diabetes, Graves' disease and Hashimoto's thyroiditis as well as in APECED syndrome. Clinical Endocrinology 200154 335-338.
26 Bøe AS, Knappskog PM, Myhre A-G, Sørheim JI \& Husebye ES. Mutational analysis of the autoimmune regulator (AIRE) gene in sporadic autoimmune Addison's disease can reveal patients with unidentified autoimmune polyendocrine syndrome type I. European Journal of Endocrinology 2002146 519-522.

27 Söderbergh A, Rorsman F, Halonen M, Ekwall O, Björses P, Kämpe $\mathrm{O}$ et al. Autoantibodies against aromatic L-amino acid decarboxylase identifies a subgroup of patients with Addison's disease. Journal of Clinical Endocrinology and Metabolism 2000 85 460-463.

28 Ekwall O, Hedstrand H, Haavik J, Perheentupa J, Betterle C, Gustafsson J et al. Pteridin-dependent hydroxylases as autoantigens in autoimmune polyendocrine syndrome type I. Journal of Clinical Endocrinology and Metabolism 200085 2944-2950.

29 Skoldberg F, Portela-Gomes GM, Grimelius L, Nilsson G, Perheentupa J, Betterle C et al. Histidine decarboxylase, a pyridoxal phosphate-dependent enzyme, is an autoantigen of gastric enterochromaffin-like cells. Journal of Clinical Endocrinology and Metabolism $2003 \mathbf{8 8} 1445-1452$.

30 Gianani R \& Eisenbarth GS. Autoimmunity to gastrointestinal endocrine cells in autoimmune polyendocrine syndrome type I. Journal of Clinical Endocrinology and Metabolism $2003 \mathbf{8 8}$ $1442-1444$.

31 Husebye ES, Bøe AS, Rorsman F, Kämpe O, Aakvaag A, Rygh T et al. Inhibition of L-amino acid decarboxylase activity by human autoantibodies. Clinical and Experimental Immunology $2000120420-423$.

32 Liiv I, Teesalu K, Peterson P, Clemente MG, Perheentupa J \& Uibo R. Epitope mapping of cytochrome P450 cholesterol sidechain cleavage enzyme by sera from patients with autoimmune polyglandular syndrome type 1. European Journal of Endocrinology 2002146 113-119.

33 Wedlock N, Asawa T, Baumann-Antczak A, Rees Smith B \& Furmaniak J. Autoimmune Addison's disease. Analysis of autoantibody binding sites on human steroid 21-hydroxylase. FEBS Letters $1993332123-126$.

34 Furmaniak J, Sanders J \& Rees Smith B. Autoantigens in the autoimmune endocrinopathies. In Contemporary Endocrinology: Autoimmune Endocrinopathies, ch 8, pp 183-216. Ed. R Volpé. Totowa, NJ: Humana Press Inc, 1999.

35 Powell AM \& Black MM. Epitope spreading: protection from pathogens, but propagation of autoimmunity? Clinical and Experimental Dermatology 200126 427-433.

Received 18 June 2003

Accepted 4 December 2003 